\title{
Continuous increase in HIV-1 incidence after the year 2000 among men who have sex with men in Rome: insights from a 25-year retrospective cohort study
}

M Giuliani (giuliani@ifo.it) ${ }^{1}$, M F Vescio ${ }^{2}$, A Latini ${ }^{1}$, G Palamara ${ }^{1}$, F Pimpinelli ${ }^{3}$, M G Donà $^{1}$, F Stivali ${ }^{1}$, F Carduccelli ${ }^{4}$, F Ensoli ${ }^{3}$,

A Di Carlo5, G Rezza ${ }^{2}$

1. STI/HIV Unit, San Gallicano Dermatological Institute, Rome, Italy

2. Infectious Diseases Department (MIPI), Istituto Superiore di Sanità, Rome, Italy

3. Laboratory of Pathology and Microbiology, San Gallicano Dermatological Institute, Rome Italy

4. Circolo Mario Mieli-NGO, Rome Italy

5. Scientific Direction Unit, San Gallicano Dermatological Institute, Rome Italy

Citation style for this article:

Giuliani M, Vescio MF, Latini A, Palamara G, Pimpinelli F, Donà MG, Stivali F, Carduccelli F, Ensoli F, Di Carlo A, Rezza G. Continuous increase in HIV-1 incidence after the year 2000 among men who have sex with men in Rome: insights from a 25-year retrospective cohort study. Euro Surveill. 2014;19(47):pii=20969. Available online: http://www.eurosurveillance.org/ViewArticle.aspx?Articleld=20969

To assess trends in HIV-1 incidence and risk factors for seroconversion among men who have sex with men (MSM) resident in Rome, Italy, a retrospective longitudinal cohort study was conducted over 25 years. Incidence rates and trends were modelled using Poisson regression and risk factors were assessed by multivariate Cox models. Of 1,862 HIV-1-negative individuals, 347 seroconverted during follow-up. HIV-1 incidence rates increased from 5.2/100 persons/year $(\mathrm{p} / \mathrm{y})$ in 1986 (95\% confidence interval (Cl): 2.3-11.5) to $9.2 / 00 \mathrm{p} / \mathrm{y}$ in 1992 ( $95 \% \mathrm{Cl}: 6.4-13.0$ ), decreased to $1.3 / 100 \mathrm{p} / \mathrm{y}$ in 2001 and increased until 2009 (11.7/100 $\mathrm{p} / \mathrm{y} ; 95 \% \mathrm{Cl}$ : 7.4-18.6). The risk of HIV-1 seroconversion increased during the study period in younger MSM (incidence rate ratio $($ IRR $)=17.18 ; 95 \% \mathrm{Cl}$ : 9.74-30.32 in $16-32$ year-olds and IRR $=5.09 ; 95 \% \mathrm{Cl}: 2.92-8.87$ in 33-41 year-olds) and in those who acquired syphilis (IRR = 7.71; 95\% Cl: 5.00-11.88). In contrast, the risk of seroconversion decreased among highly educated MSM (IRR $=0.54 ; 95 \% \mathrm{Cl}: 0.35-0.82)$ and those without Italian citizenship (IRR $=0.45 ; 95 \% \mathrm{Cl}: 0.28-0.71$ ). The HIV epidemic in MSM living in Rome continues to expand. Targeted prevention programmes against sexually transmitted infections to enhance knowledge transfer and behavioural skills are urgently required.

\section{Introduction}

In Europe, human immunodeficiency virus (HIV) incidence declined among men who have sex with men (MSM) after the first phase of the epidemic because of a decrease in risky sexual practices [1]. This decline continued until the mid-1990s when the introduction of combination antiretroviral therapy (cART) dramatically changed the quality of life and survival of infected individuals and boosted the re-emergence of sexual risk behaviour which exposed MSM to sexually transmitted infections (STI) in general and HIV-1 in particular [2-5]. National surveillance systems and observational studies suggest that since the early 2000s, HIV-1 incidence among MSM has been increasing in highincome countries, including many European countries, Australia, and the United States (US), thus causing the epidemic to re-emerge [6]. In developed countries, incidence rates of HIV-1 infection are therefore disproportionately higher among MSM than in other sexually active adult populations, despite decades of public health efforts and the benefits, after 1996, of cART on the transmission risk of HIV-1 [7-9].

In Italy, ca 1,200-1,300 MSM acquire HIV infection every year, and in 2011, nearly $40 \%$ of the newly diagnosed HIV cases were MSM. Moreover, the proportion of HIV infections attributable to sex with a same-sex male partner almost doubled from 2000 to $2011[10,11]$.

\section{FIGURE 1}

Fitted HIV-1 incidence trend in men who have sex with men repeatedly tested in Rome, Italy, 1985-2009 $(\mathrm{n}=1,862)$

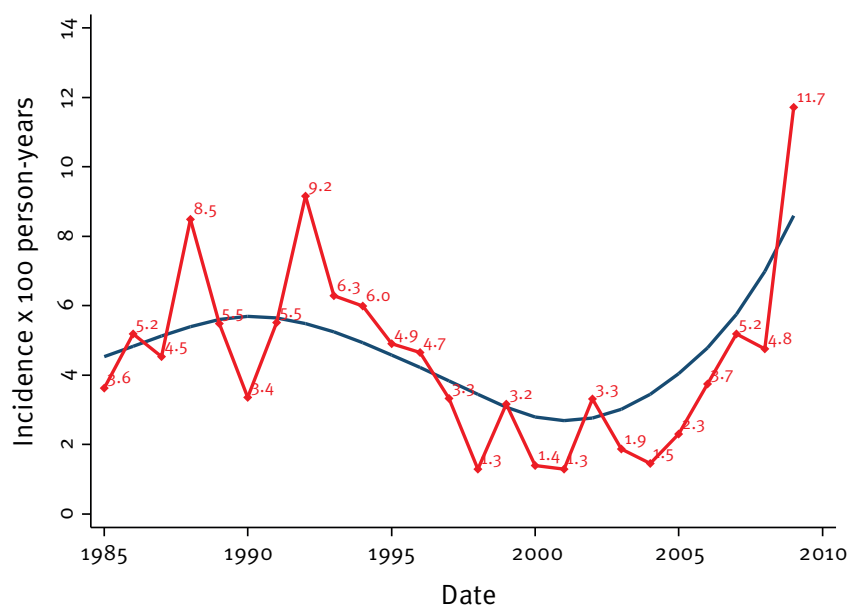


Although rates of HIV infection among MSM decreased until the late 1990s, data for the period after 2000 indicate an increase in the occurrence of HIV infection in this population, which is consistent with the re-emergence of ulcerative STIs in the same period $[4,12]$.

To assess HIV- 1 incidence trends and risk factors among MSM living in Rome, a cohort of individuals repeatedly tested for HIV antibodies was identified among a large population of men attending a structured HIV screening programme in the largest STI clinic of the city. The following study contains data from a 25 -year follow-up period.

\section{Methods}

Site recruitment and study population

Of the MSM attending the STI clinic of the San Gallicano Dermatological Institute in Rome, Italy between April 1984 and December 2010 who were tested for HIV-1 antibodies at least twice and were negative in the first test, we included opportunistically in the study all those who had never used drugs intravenously. The site of enrolment represents an important counselling and testing service for at-risk groups such as STI patients, MSM and migrants, who voluntarily access an ongoing HIV-1 screening programme. The centre's activity is directed at an urban population of more than 2.5 million inhabitants and its catchment population comprises also patients from other regions in Italy and from abroad (ca 20\%).

Study participants were men who stated they had had anal sex with at least one male partner during the six months before the first HIV-1 antibody test. Two thirds of them perceived themselves to be at risk because of their sexual behaviour and therefore repeatedly selfreferred to our STI centre for HIV testing. Other participants were individuals to whom HIV testing was offered because of their self-reported risky behaviour or a diagnosis of an STI. During the study period, recruitment was promoted according to the methodology of 'snowball' sampling, also in collaboration with non-governmental associations for human and health rights of MSM. At local level, brochures and leaflets were used to advertise the screening programme and to sustain the peer-to-peer recruiting. The 'snowball' procedure was used during the whole duration of the study. At each visit, participants were also visited and managed for the risk of other STIs according to the European guidelines for STI diagnosis and treatment [13]. In this context, participants were screened for Treponema pallidum infection and for rectal and pharyngeal Neisseria gonorrhoeae infection. Blood samples for serological tests and biological samples were collected from all participants.

\section{Ethics statement}

The study was approved by the San Gallicano Dermatological Institute Ethics Committee and performed in compliance with the Helsinki Declaration.
Informed consent was obtained from all participants according to Italian law concerning strategies for HIV-1 counselling and testing.

\section{Data collection}

During each consultation, a standardised questionnaire, administered face-to-face by an interviewer, was used to collect information on demographics, medical history, lifestyle (i.e. alcohol and/or intravenous drug use) and sexual behaviour (i.e. sexual practices, total number of partners ever, number of partners in the previous six months, characteristics of sexual partnership etc.). For all participants, additional clinical data were also retrieved from individual medical records available in the electronic clinical archive of the STI clinic.

\section{Laboratory testing}

Blood samples were tested for HIV-1 antibodies using consecutive generations of commercially available screening assays (Abbott Laboratories, Illinois, US; Abbott Park, Illinois, US; bioMérieux, France). All seroreactive samples were confirmed by Western blot (Genelabs Diagnostics, Singapore). Participants were screened for T. pallidum infection by serological assays (Rapid Protein Reagin (RPR), Treponema Pallidum Haemagglutination Assay (TPHA), IgG and IgM) and for rectal and pharyngeal $N$. gonorrhoeae infection by culturing samples from anal and throat swabs.

\section{Statistical analysis}

Incidence rates were calculated using the personyears $(\mathrm{p} / \mathrm{y})$ approach for MSM who were HIV-negative at enrolment and who underwent at least one additional HIV test during the study period. Time at risk was defined as the difference between the date of the first (entry into the study) and the last blood test (exit from the study). Because the exact time of seroconversion was not known, we assumed that HIV seroconverters were at risk for half the interval between the last negative and the first positive HIV test. HIV incidence was computed from 1985 to 2009. To minimise potential biases in the rates estimated at the two extremes of the study period, the first (1984) and the last (2010) year were excluded from the analysis of the HIV-1 trend owing to the potential incompleteness of

\section{TABLE 1}

Modelling of HIV-1 incidence rate curves in men who have sex with men in three calendar periods using Poisson regression, Rome, Italy, 1985-2009 $(\mathrm{n}=1,862)$

\begin{tabular}{|l|c|c|c|}
\hline $\begin{array}{l}\text { Calendar } \\
\text { period }\end{array}$ & IRR $_{\text {adjusted }}$ & $95 \% \mathrm{Cl}$ & p value \\
\hline $1985-1992$ & 1.07 & $1.00-1.16$ & 0.059 \\
\hline $1993-2000$ & 0.72 & $0.65-0.81$ & $<0.001$ \\
\hline $2001-2009$ & 1.56 & $1.40-1.75$ & $<0.001$ \\
\hline
\end{tabular}

$\mathrm{Cl}$ : confidence interval; IRR: incidence rate ratio.

IRR per year within the selected period was adjusted by age at the time of diagnosis. 
Fitted HIV-1 incidence trend in men who have sex with men, by age group (A) and selected birth cohorts (B), Rome, Italy, 1985-2009 ( $\mathrm{n}=1,862)$

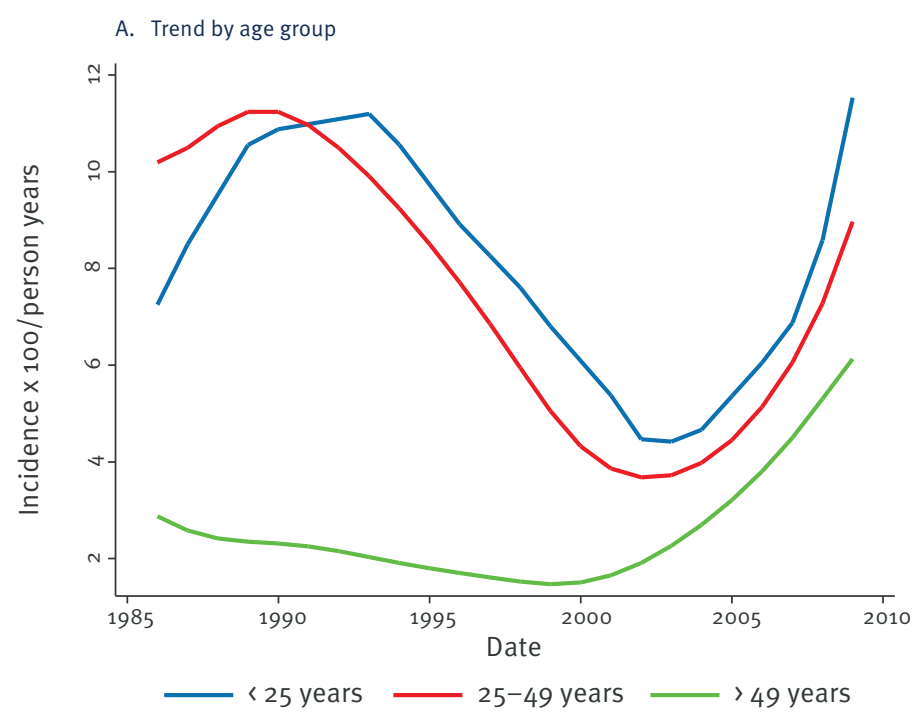

B. Trend by birth cohort

follow-up data. Because incidence estimates varied greatly from year to year, the incidence trend over time was obtained using the locally weighted scatterplot smoothing (Lowess) technique. In addition, the incidence trend was modelled using Poisson regression with the calendar year as a continuous variable and allowing smoothing of varying trends via linear splines. The model was adjusted according to age at HIV seroconversion, included in the regression as a continuous covariate and modelled using linear splines.

Specific incidence rate ratios (IRR) for HIV-1 seroconversion were calculated for participants who were free of syphilis or gonorrhoea (any sites) at the beginning of the study and who acquired either syphilis or gonorrhoea during the study period. The date of diagnosis was used to estimate the time at risk for each participant. The follow-up of a given individual who became infected with syphilis was split into an exposed and an unexposed period. In the same way, the follow-up for gonorrhoea was split into an exposed and an unexposed period. Potentially predictive variables for HIV seroconversion identified in univariate analyses were included in a multivariate Cox proportional hazards model and adjusted IRR were calculated. All statistical analyses were conducted using STATA statistical package 11 (Stata Corporation 2009. Stata Statistical Software Release \#11. College Station, TX: StataCorp LP).

\section{Results}

From April 1984 to December 2010, 4,352 MSM attended the HIV screening programme of the STI clinic of the San Gallicano Dermatological Institute in Rome, Italy. Among them, 1,862 HIV-seronegative MSM were tested more than once and qualified for inclusion in the longitudinal study. The total time at risk for the participant population was $8,638.4$ years. The median number of
HIV tests received over time by the study participants was 3.0 (interquartile range (IQR): 2-6) and the median follow-up time was 2.76 years (IQR:0.92-5.50). No change in the median number of tests per individual was observed during the study period. A total of 347 HIV-1 incident infections were observed, with an overall seroincidence rate (IR) of 4.0 (95\% confidence interval (Cl): 3.6-4.5) per $100 \mathrm{p} / \mathrm{y}$.

\section{HIV-1 incidence trend analysis}

The annual incidence rates showed relevant changes during the 25-year study period. At the beginning, HIV incidence increased from 5.2 per $100 \mathrm{p} / \mathrm{y}(95 \% \mathrm{Cl}$ : 2.3-11.5) in 1986 to 9.2 per $100 \mathrm{p} / \mathrm{y}$ (95\% Cl: 6.4-13.0) in 1992. After 1992, the incidence decreased progressively to 1.3 per $100 \mathrm{p} / \mathrm{y}$ in 2001. After 2001, the incidence showed a progressive increase and reached a peak in 2009 at 11.7 per $100 \mathrm{p} / \mathrm{y}$ (95\% Cl: 7.4-18.6). The decennial fitted HIV-1 incidence curve, obtained after smoothing correction, made it possible to define a trend with an initial mild increase until 1992, followed by a decrease until 2001 and a noticeable increase in incidence until 2009 (Figure 1).

The Poisson regression analysis adjusted according to age at HIV seroconversion showed a slight increase in the HIV-1 incidence rate from 1985 to 1992 (the IRR was 1.07 per calendar year; $95 \% \mathrm{Cl}: 1.00-1.16 ; \mathrm{p}=0.05)$ and a significant decrease from 1993 to 2000 (IRR=0.72; $95 \% \mathrm{Cl}: 0.65-0.81 ; \mathrm{p}<0.001)$. From 2001 onwards, the HIV-1 incidence rate increased significantly until 2009 $(I R R=1.56 ; 95 \% \mathrm{Cl}: 1.40-1.75 ; \mathrm{p}<0.001)$ (Table 1). No significant difference in the median time at risk per individual was calculated in the three different calendar periods of analysis (1985-1992: 2.81 years (2.503.16); 1993-2000: 3.08 years (2.87-3.29); 2001-2009: 2.90 years $(2.71-3.09))$. 
Characteristics of men who have sex with men repeatedly tested for HIV-1 antibodies, by HIV status at the end of the study period, Rome, Italy, $1985-2009(\mathrm{n}=1,862)$

\begin{tabular}{|c|c|c|c|c|c|}
\hline & $\begin{array}{c}\text { Non } \\
\text { HIV-seroconverters } \\
(n=1,515)\end{array}$ & $\begin{array}{c}\text { HIV } \\
\text { seroconverters } \\
(n=347)\end{array}$ & IRR & $(95 \% \mathrm{Cl})$ & $\mathrm{p}$ value \\
\hline Age at diagnosis in years ${ }^{\mathrm{a}, \mathrm{b}}$ : median (range) & $36(29-44)$ & $34(29-40)$ & 0.94 & $0.93-0.95$ & $<0.001$ \\
\hline \multicolumn{6}{|l|}{ Age at diagnosis ${ }^{a}$, tertiles: $\mathrm{n}(\%)$} \\
\hline$>41$ years & $505(33)$ & $81(23)$ & 1 & - & - \\
\hline $33-41$ years & $502(33)$ & $140(40)$ & 2.33 & $1.58-3.44$ & $<.001$ \\
\hline $16-32$ years & $508(33)$ & $126(36)$ & 4.99 & $3.46-7.19$ & $<0.001$ \\
\hline \multicolumn{6}{|l|}{ Educational levelc: $n(\%)$} \\
\hline Low & $253(20)$ & $83(30)$ & 1 & - & - \\
\hline Medium & $652(52)$ & $147(53)$ & 0.89 & $0.66-1.20$ & 0.454 \\
\hline High & $360(28)$ & $45(16)$ & 0.46 & $0.31-0.68$ & $<0.001$ \\
\hline \multicolumn{6}{|l|}{ Nationality: $\mathrm{n}(\%)$} \\
\hline Italian & $1,196(79)$ & $299(86)$ & 1 & - & - \\
\hline Non-Italian & $319(21)$ & $48(14)$ & 0.49 & $0.34-0.70$ & $<0.001$ \\
\hline Age at first intercourse in years ${ }^{\mathrm{b}}$ : median (range) & $18(16-25)$ & $17(16-22)$ & 0.96 & $0.94-0.97$ & $<0.001$ \\
\hline \multicolumn{6}{|l|}{ History of selected STId: $\mathrm{n}(\%)$} \\
\hline No & $1,457(96)$ & $323(93)$ & 1 & - & - \\
\hline Yes & $58(4)$ & $24(7)$ & 0.96 & $0.60-1.52$ & 0.873 \\
\hline \multicolumn{6}{|l|}{ History of gonorrhoea (any sites): $\mathrm{n}(\%)$} \\
\hline No & $1,499(99)$ & $340(98)$ & 1 & - & - \\
\hline Yes & $16(1)$ & $7(2)$ & 1.22 & $0.52-2.86$ & 0.660 \\
\hline \multicolumn{6}{|l|}{ History of syphilis: $\mathrm{n}(\%)$} \\
\hline No & $1,469(97)$ & $327(94)$ & 1 & - & - \\
\hline Yes & $46(3)$ & $20(6)$ & 0.93 & $0.57-1.53$ & 0.786 \\
\hline \multicolumn{6}{|l|}{ Occurrence of syphilise $: \mathrm{n}(\%)$} \\
\hline No & $1,048(69)$ & $241(69)$ & 1 & - & - \\
\hline Yes & $467(31)$ & $106(31)$ & 1.69 & $1.31-2.19$ & $<0.001$ \\
\hline \multicolumn{6}{|l|}{ Occurrence of gonorrhoeae: n (\%) } \\
\hline No & $1,270(84)$ & $290(84)$ & 1 & - & - \\
\hline Yes & $245(16)$ & $57(16)$ & 1.79 & $1.29-2.47$ & $<0.001$ \\
\hline
\end{tabular}

$\mathrm{Cl}$ : confidence interval; IRR: incidence rate ratio; STI: sexually transmitted infections.

Subtotals differ depending on how the number of individuals for whom the information was known.

a For non-seroconverted individuals, the age at last HIV-negative test is shown.

b Age at diagnosis/first intercourse was used as continuous variable.

Information missing for 72 HIV-infected and 250 HIV-uninfected individuals.

At enrolment. The STIs investigated includes: syphilis, gonorrhoea (any sites), genital herpes, genital warts, non-gonococcal genital infections and chlamydia.

e During follow-up period.

Using the smoothing curve, the analysis adjusted according to age at HIV seroconversion showed that the increase in incidence from 1985 to 1992 was mainly sustained by individuals who were younger than 25 years and by those aged 25 to 49 years (Figure $2 \mathrm{~A}$ ). For the young MSM, a peak in incidence was reached in 1993 (incidence rate $(\mathrm{IR})=11.3 ; 95 \% \mathrm{Cl}: 7.0-35.1$ ). In contrast, in MSM aged 25 to 49 years, the peak was reached already in 1989 ( $I R=11.6 ; 95 \% \mathrm{Cl}: 4 \cdot 9-18.5)$. MSM older than 49 years did not contribute to the observed increase in incidence; the annual incidence rate in this age group decreased constantly from 1985 to 2000 (Figure 2A). After 1992, HIV incidence among MSM up to 49 years of age decreased progressively until 2001; thereafter, incidences in all age groups showed a dramatic increase until 2009. Surprisingly, after 2000 , for the first time since 1985 , the oldest age group also showed an increase in HIV incidence from ca 0.5 per $100 \mathrm{p} / \mathrm{y}(95 \% \mathrm{Cl}: 0.15-3.5)$ in 2001 to $6.1 \mathrm{per}$ $100 \mathrm{p} / \mathrm{y}(95 \% \mathrm{Cl}: 1.3-20.5)$ in 2009, which is consistent with the level of increase found for the other age groups. 
The trend analysis by birth cohort was consistent with the findings observed when stratifying the data according to age group and showed that all the three selected birth cohorts contributed to the increase in the HIV-1 incidence after 2001. This increase was mostly due to MSM born after 1975 who were tested for the first time after 1995 (Figure 2B). HIV-1 incidence curves for the birth cohorts of MSM born before 1960 and between 1960 and 1974 were almost parallel and consistent with the overall trend (Figure 1). In contrast, the HIV-1 trend for the birth cohort born after 1974 showed a rapid decrease from 1995 to 2000 , followed by a rapid increase until 2009 .

\section{Risk factor analysis}

No difference in the median number of HIV tests performed was observed between seroconverters and non-seroconverters (3.0 vs 3.0, $\mathrm{OR}=1.01 ; 95 \% \mathrm{Cl}$ : $0.98-1.03)$. For seroconverters, the median time of infection was 1.72 years (IQR: 0.47-3.93) following enrolment. No difference in median age between HIV seroconverters and non-seroconverters (35.4 years vs 35.2 years) was observed. In addition, no statistically significant difference in the number of sexual partners (both lifetime and in the six months preceding the HIV tests), in the proportion of condom use per sexual act, and in the characteristics of partnership were observed between HIV seroconverters and non-seroconverters (data not shown).

Other demographic characteristics and risky sexual behaviour of the participants by HIV status at the end of the study are presented in Table 2. The risk of HIV infection increased inversely with the age at diagnosis. Compared with MSM older than 41 years, the incidence rate was more than doubled $(I R R=2.33)$ for those aged 33 to 41 years and five times higher $(I R R=4.99)$ for those aged 16 to 32 years. Moreover, the risk of HIV-1 seroconversion was reduced by half in individuals with a high educational level $(I R R=0.46)$ and in those who were not Italian citizens $(I R R=0.49)$. No significant difference in the risk of seroconversion was observed between individuals with a history of STIs at enrolment compared with those with no history of STIs. However, a significant increase in the risk of HIV-1 infection was found among MSM who became infected with syphilis (IRR=1.69; 95\%Cl: $1.31-2.19)$ or gonorrhoea $(\mathrm{IRR}=1.79$; $95 \% \mathrm{Cl}: 1.29-2.47)$ during the study period.

Potential confounders for HIV-1 seroconversion were included in the multivariate Cox model. Independent risk factors for HIV-1 seroconversion in MSM living in Rome included: young age, low educational level, Italian nationality and occurrence of syphilis and/or gonorrhoea during the year preceding HIV-1 seroconversion (Table 3).

More specifically, our data confirmed that the risk of becoming HIV-infected increased inversely with the age at the diagnosis. The incidence rate was 17 times higher in MSM younger than 33 years and five times
TABLE 3

Multivariate analysis of risk factors for HIV infection among men who have sex with men with no history of injecting drugs, Rome, Italy, 1985-2009 $\left(n=1,540^{a}\right)$

\begin{tabular}{|c|c|c|c|}
\hline & IRR $_{\text {adjusted }}$ & $95 \% \mathrm{Cl}$ & $\mathrm{p}$ value \\
\hline \multicolumn{4}{|c|}{ Age at diagnosis in years (tertiles) } \\
\hline$>41$ & 1 & - & - \\
\hline $33-41$ & 5.09 & $2.92-8.87$ & $<0.001$ \\
\hline $16-32$ & 17.18 & $9.74-30.32$ & $<0.001$ \\
\hline \multicolumn{4}{|l|}{ Educational level } \\
\hline Low & 1 & - & - \\
\hline Medium & 0.92 & $0.68-1.25$ & 0.593 \\
\hline High & 0.54 & $0.35-0.82$ & 0.004 \\
\hline \multicolumn{4}{|l|}{ Nationality } \\
\hline Italian & 1 & - & - \\
\hline Non-Italian & 0.45 & $0.28-0.71$ & 0.001 \\
\hline \multicolumn{4}{|c|}{ Occurrence of gonorrhoeab (any sites) } \\
\hline No & 1 & - & - \\
\hline During the year preceding SC & 1.66 & $1.01-2.71$ & 0.045 \\
\hline More than one year before SC & 1.63 & $1.06-2.49$ & 0.025 \\
\hline \multicolumn{4}{|l|}{ Occurrence of syphilis ${ }^{b}$} \\
\hline No & 1 & - & - \\
\hline During the year preceding SC & 7.71 & $5.00-11.88$ & $<0.001$ \\
\hline More than one year before SC & 1.16 & $0.83-.62$ & 0.376 \\
\hline \multicolumn{4}{|l|}{ Birth cohort } \\
\hline After 1974 & 1 & - & - \\
\hline $1960-1974$ & 0.33 & $0.22-0.50$ & $<0.001$ \\
\hline Before 1960 & 0.14 & $0.07-0.25$ & $<0.001$ \\
\hline
\end{tabular}

$\mathrm{Cl}$ : confidence interval; IRR: incidence rate ratio; SC: HIV-1 seroconversion.

Missing values on educational level for 322 individuals.

During follow-up period.

higher in those aged 33 to 41 years compared with the oldest age group. Similarly, MSM born after 1974 and those born between 1960 and 1974 showed a seven and three times higher risk of seroconversion compared with those born before 1960 .

Furthermore, the risk of becoming HIV-1-infected was twice as high for MSM with a low educational level and for Italian citizens than for MSM with a high educational level $\left(I R R_{\text {adjusted }}=0.54\right)$ and those with other citizenship (IRR adjusted $\left._{\text {}}=0.45\right)$.

The multivariate analysis confirmed a dramatic increase in the risk of becoming infected with HIV after acquiring syphilis. In particular, the risk increased ca eight-fold for the first year $\left(I_{R} R_{\text {adjusted }}=7.71\right)$ and ca 13 -fold $\left(I R_{\text {adjusted }}=13.5\right.$, data not listed in the Tables) for the first six months since diagnosis of syphilis, but decreased after the first year, matching the risk for syphilis-free MSM (IRR $\left.R_{\text {adjusted }}=1.16\right)$. A smaller but statistically significant increase in the risk of HIV-1 seroconversion was also observed for subjects who had 
contracted gonorrhoea during the year before HIV-1 seroconversion ( $\left.I R R_{\text {adjusted }}=1.66\right)$.

\section{Discussion}

Our longitudinal study on MSM living in Rome has provided valuable insights about the dynamics and the characteristics of the HIV epidemic in this urban population over the last 25 years. Preliminary data from this cohort about HIV-1 trends until 2003 have already been published previously [12].

Between 1985 and 1992, the first period of virus circulation in Italy, we observed a slight increase in HIV-1 incidence year by year. This is consistent with other studies which suggest that the HIV epidemic among MSM in southern Europe started later than in northern Europe and the US. In particular, our findings differ from those of the Dutch cohort of MSM in Amsterdam, where the incidence rates were higher in the first half of the 1980 s and decreased between 1985 and 1992 [14].

The fast and progressive decline in HIV-1 incidence rates in our cohort between 1992 and 2001 was also described in other Western countries and can be attributed to important behavioural changes in MSM populations who adopted stable safe sexual practices in the 1990s, a fact reported in several large studies [2,15-17]. Finally, we observed a dramatic increase in HIV-1 incidence after 2001 and until 2009, consistent with our previous findings collected in the same population until 2003 [12].

This increase in incidence observed in MSM in Italy is in accordance with observations from other European studies despite different methodological approaches $[9,18]$. The trend was larger and accelerated among younger MSM, although it was observed for all the age groups, including those 50 years and older, who did not contribute to the increase in HIV-incidence at the beginning of the study period (from 1985 to 1992).

The dramatic increase in incidence measured since 2001 coincided with the re-emergence of bacterial STIs, such as syphilis and gonorrhoea observed among MSM living in Rome from 2000 to 2007 [4, and data not shown. Similar findings apply to other European countries during the same period $[19,20]$. We observed that the risk of acquiring HIV-1 infection was higher among MSM who contracted syphilis during followup than for those remaining syphilis-free until the end of the study. The presence of these genital ulcerative lesions and the increased number of inflammatory cells, which enhance the potential for HIV transmission in MSM who contracted syphilis, may explain the higher HIV rates that we and other authors found for these subjects $[5,21]$. Besides the biological synergism between syphilis and HIV, the high number of Italian MSM who contracted HIV-1 infection within six months of being diagnosed with syphilis may also be due to the fact that both infections share a common route of transmission and pattern of risk factors, and that social networks of persons with syphilis or at risk for syphilis are also at higher risk for HIV infection, a fact also reported in a 12-month prospective study in Chinese MSM from 2006 to 2007 [22]. Another obvious explanation may be heightened perception of being at risk for HIV-1 and/or other sexually transmitted infections among individuals already diagnosed with syphilis, which would lead at first to a larger number of MSM being tested and consequently to an earlier diagnosis of HIV, and later to a change in sexual behaviour. The adoption of safer sexual practices as a response to educational programmes to which MSM were enrolled after the diagnosis of primary or secondary syphilis may also explain why the risk of becoming infected with HIV-1 dramatically declined within the first year since diagnosis of syphilis.

The association between the occurrence of gonorrhoea and the risk of HIV-1 seroconversion is consistent with data from the Amsterdam Cohort Study, although Dutch MSM who had contracted gonorrhoea in the six months before seroconversion had a much higher risk than that observed in our study [14]. The risk of HIV-1 seroconversion increased after the diagnosis of gonorrhoea and remained stable for MSM who had contracted gonorrhoea in the year before seroconversion, suggesting that gonorrhoea may be considered as a proxy for risky sexual practices but, in contrast to syphilis, did not increase the biological susceptibility of seronegative individuals for HIV.

Other relevant predictors of HIV-1 seroconversion in our cohort were young age, low educational level and Italian nationality. After 2000, association of young age with a higher risk of HIV-1 infection was reported in several incidence studies in Europe $[14,23]$ and in the US [24], perhaps due to a lower ratio of condom use per sexual act in the young population [14,25], the way young individuals select partners (i.e. Internetbased recruitment of partners) $[26,27]$ or their specific psychosocial attitudes (i.e. involvement in the homosexual community, importance of gay identity, self-homophobia) [28]. To the same extent, a low educational level was found to increase the risk of HIV-1 seroconversion in other European studies [14].

Our study may have suffered from some limitations and biases. Firstly, the repeatedly tested MSM in our longitudinal cohort study may not be representative of the whole MSM population living in Rome. In fact, our data probably describe the circulation of HIV-1 in a subpopulation of MSM with an increased risk of sexually transmitted infections. Nor can we exclude that attending an HIV-1 monitoring programme which offers counselling activities aimed at the reduction of sexual risk behaviour may reduce the risk of HIV-1 infection so that our population may have been at a lower risk than the general MSM population in Rome. Secondly, the individual data collection form, defined more than two decades ago, may have failed to evidence the role of 
certain risk factors for HIV-1 infection, especially those relevant among the homosexual communities in recent years (i.e. non-injection recreational drugs use, choosing sexual partners using the Internet or serosorting practice).

Despite these limitations, our findings suggest that, in accordance with the re-emergence of syphilis and gonorrhoea observed in Rome after 2000, particularly among young Italian MSM with a low educational level, HIV-1 infection continues to be contracted disproportionately more frequently by the homosexual community in Rome. These findings highlight the need for improved monitoring systems for HIV-1 risk in urban communities of MSM and more effective interventions targeted at limiting the circulation of other STIs in this population and to prevent waning of the benefits of ART on the HIV-1 transmission rate at community level.

We have started in mid-2011 a programme with multiple approaches based on opt-out strategies for HIV testing, outreach testing by a rapid saliva-based assay and the reduction of barriers to accessibility for MSM to our STI clinic (also supported by local non-governmental organisations for homosexuals) to decrease the fraction of MSM unaware of their HIV infection, to increase the number of individuals tested for the first time, and to reduce the span between last negative and first positive HIV-1 antibody tests among those tested more than once. In addition, continuing behavioural interventions are needed to improve basic information and attitudes to promote persistent condom use in the homosexual community in Rome, particularly among the young and those with low educational level as well as among HIV-1 infected MSM.

\section{Acknowledgements}

The authors wish to thank everyone who, along the last 25 years, participates in this HIV-1 longitudinal screening programme, in particular all the physicians, microbiologists and public health doctors who consulted and contacted the study participants from 1984 to 2010. In particular we want to thank: Prof. Federico Caprilli, Dr Giulio Gentili, Dr Grazia Prignano, Dr Antonio Maini, Dr Bruno Capitanio, Dr Amalia Giglio and Dr Silvana Trincone for their precious collaboration.

The authors declare that they have no competing interests. The study was partially supported by a Research Grant from GILEAD Ltd. (Cod.IFO:12/09/G/2; CUP:H51)110005200007).

\section{Conflict of interest}

None declared.

\section{Authors' contributions}

MG and GR conceived and designed the study, MG and MFV performed the data analysis and interpreted the results, MG, MFV and GR prepared the manuscript for publication, MG, AL, GP and ADC consulted patients and collected clinical and behavioural data after 2000 , FP and FE carried out the laboratory work and performed the serological and microbiological analyses, MGD, FS and FC contributed to data input and management. All authors have read and approved the final version of the manuscript.

\section{References}

1. Page-Shafer K, Veugelers PJ, Moss AR, Strathdee S, Kaldor JM, van Griensven GJ. Sexual risk behavior and risk factors for HIV-1 seroconversion in homosexual men participating in the Tricontinental Seroconverter Study, 1982-1994. Am J Epidemiol. 1997;146(7):531-42. http://dx.doi.org/10.1093/oxfordjournals. aje.a009311 PMID:9326430

2. Dilley JW, Woods WJ, McFarland W. Are advances in treatment changing views about high-risk sex? N Engl J Med. 1997;337(7):501-2. http://dx.doi.org/10.1056/ NEJM199708143370715 PMID:9254339

3. Stolte IG, Dukers NH, Geskus RB, Coutinho RA, de Wit JB. Homosexual men change to risky sex when perceiving less threat of HIV/AIDS since availability of highly active antiretroviral therapy: a longitudinal study. AIDS. 2004;18(2):303-9. http://dx.doi.org/10.1097/00002030 200401230-00021 PMID:15075549

4. Giuliani M, Palamara G, Latini A, Maini A, Di Carlo A. Evidence of an outbreak of syphilis among men who have sex with men in Rome. Arch Dermatol. 2005;141(1):100-1. http://dx.doi. org/10.1001/archderm.141.1.100 PMID:15655156

5. Stolte IG, Dukers NH, de Wit JB, Fennema JS, Coutinho RA. Increase in sexually transmitted infections among homosexual men in Amsterdam in relation to HAART. Sex Transm Infect. 2001;77(3):184-6. http://dx.doi.org/10.1136/sti.77.3.184 PMID:11402225

6. Sullivan PS, Hamouda O, Delpech V, Geduld JE, Prejean J, Semaille C, et al.; Annecy MSM Epidemiology Study Group. Reemergence of the HIV epidemic among men who have sex with men in North America, Western Europe, and Australia, 1996-2005. Ann Epidemiol. 2009;19(6):423-31. http://dx.doi. org/10.1016/j.annepidem.2009.03.004 PMID:19460672

7. Beyrer C, Baral SD, Walker D, Wirtz AL, Johns B, Sifakis F. The expanding epidemics of HIV type 1 among men who have sex with men in low- and middle-income countries: diversity and consistency. Epidemiol Rev. 2010;32(1):137-51. http://dx.doi. org/10.1093/epirev/mxq011 PMID:20573756

8. Fisher M, Pao D, Murphy G, Dean G, McElborough D, Homer $\mathrm{G}$, et al. Serological testing algorithm shows rising HIV incidence in a UK cohort of men who have sex with men: 10 years application. AIDS. 2007;21(17):2309-14. http://dx.doi. org/10.1097/QAD.ob013e3282efgfed PMID:18090279

9. Phillips AN, Cambiano V, Nakagawa F, Brown AE, Lampe F, Rodger A, et al. Increased HIV incidence in men who have sex with men despite high levels of ART-induced viral suppression: analysis of an extensively documented epidemic. PLoS ONE. 2013;8(2):e55312. http://dx.doi.org/10.1371/journal. pone.0055312 PMID:23457467

10. Centro Operativo AIDS. Aggiornamento delle nuove diagnosi di infezione da HIV e dei casi di AIDS in Italia al 31 dicembre 2011. [New HIV infections and AIDS cases update in Italy at the December 31, 2011]. Suligoi B. (editor). Notiziario dell'Istituto Superiore di Sanită. 2012;10 Suppl.1.Italian

11. Mammone A, Pezzotti P, Angeletti C, Orchi N, Carboni A, Navarra A, et al.; SENDIH Study Group. HIV incidence estimate combining HIV/AIDS surveillance, testing history information and HIV test to identify recent infections in Lazio, Italy. BMC Infect Dis. 2012;12(1):65. http://dx.doi.org/10.1186/1471-233412-65 PMID:22433313

12. Giuliani M, Di Carlo A, Palamara G, Dorrucci M, Latini A, Prignano G, et al. Increased HIV incidence among men who have sex with men in Rome. AIDS. 2005;19(13):1429-31. http://dx.doi.org/10.1097/01.aids.0000180808.27298.af PMID:16103777

13. International Union Against Sexually Transmitted Infections (IUSTI). IUSTI Regions - Europe. [Accessed 14 November 2014]. Available from: http://www.iusti.org/regions/europe/ euroguidelines.htm

14. Jansen IA, Geskus RB, Davidovich U, Jurriaans S, Coutinho RA, Prins $\mathrm{M}$, et al. Ongoing HIV-1 transmission among men who have sex with men in Amsterdam: a 25 -year prospective cohort study. AIDS. 2011;25(4):493-501. http://dx.doi.org/10.1097/ QAD.ob013e328342fbe9 PMID:21192230

15. Winkelstein W Jr, Samuel M, Padian NS, Wiley JA, Lang W, Anderson RE, et al. The San Francisco Men's Health Study: III. Reduction in human immunodeficiency virus transmission among homosexual/bisexual men, 1982-86. Am J Public 
Health. 1987;77(6):685-9. http://dx.doi.org/10.2105/ AJPH.77.6.685 PMID:3646848

16. van Griensven GJ, de Vroome EM, Goudsmit J, Coutinho RA. Changes in sexual behaviour and the fall in incidence of HIV infection among homosexual men. BMJ. 1989;298(6668):218 21. http://dx.doi.org/10.1136/bmj.298.6668.218 PMID:2493866

17. Winkelstein W Jr, Wiley JA, Padian NS, Samuel M, Shiboski S, Ascher MS, et al. The San Francisco Men's Health Study: continued decline in HIV seroconversion rates among homosexual/bisexual men. Am J Public Health. 1988;78(11):1472-4. http://dx.doi.org/10.2105/AJPH.78.11.1472 PMID:3177723

18. Presanis AM, Gill ON, Chadborn TR, Hill C, Hope V, Logan $\mathrm{L}$, et al. Insights into the rise in HIV infections, 2001 to 2008: a Bayesian synthesis of prevalence evidence. AIDS. 2010;24(18):2849-58. http://dx.doi.org/10.1097/ QAD.ob013e32834021ed PMID:20962617

19. Fenton KA, Lowndes CM. Recent trends in the epidemiology of sexually transmitted infections in the European Union. Sex Transm Infect. 2004;80(4):255-63. http://dx.doi.org/10.1136/ sti.2004.009415 PMID:15295121

20. Marcus U, Kollan C, Bremer V, Hamouda O. Relation between the HIV and the re-emerging syphilis epidemic among MSM in Germany: an analysis based on anonymous surveillance data. Sex Transm Infect. 2005;81(6):456-7. http://dx.doi.org/10.1136/ sti.2005.014555 PMID:16326845

21. Dougan S, Evans BG, Elford J. Sexually transmitted infections in Western Europe among HIV-positive men who have sex with men. Sex Transm Dis. 2007;34(10):783-90. PMID:17495592

22. Xu JJ, Zhang M, Brown K, Reilly K, Wang H, Hu Q, et al. Syphilis and HIV seroconversion among a 12-month prospective cohort of men who have sex with men in Shenyang, China. Sex Transm Dis. 2010;37(7):432-9. PMID:20375928

23. Semaille C, Cazein F, Lot F, Pillonel J, Le Vu S, Le Strat Y, et al. Recently acquired HIV infection in men who have sex with men (MSM) in France, 2003-2008. Euro Surveill. 2009;14(48):19425. PMID:20003900

24. Ackers ML, Greenberg AE, Lin CY, Bartholow BN, Goodman $\mathrm{AH}$, Longhi $\mathrm{M}$, et al. High and persistent HIV seroincidence in men who have sex with men across 47 U.S. cities. PLoS ONE. 2012;7(4):e34972. http://dx.doi.org/10.1371/journal. pone.0034972 PMID:22529964

25. Ekstrand ML, Stall RD, Paul JP, Osmond DH, Coates TJ. Gay men report high rates of unprotected anal sex with partners of unknown or discordant HIV status. AIDS. 1999;13(12):152533. http://dx.doi.org/10.1097/00002030-199908200-00013 PMID:10465077

26. Crepaz N, Marks G, Mansergh G, Murphy S, Miller LC, Appleby $P R$. Age-related risk for HIV infection in men who have sex with men: examination of behavioral, relationship, and serostatus variables. AIDS Educ Prev. 2000;12(5):405-15. PMID:11063060

27. Garofalo R, Herrick A, Mustanski BS, Donenberg GR. Tip of the Iceberg: young men who have sex with men, the Internet, and HIV risk. Am J Public Health. 2007;97(6):1113-7. http://dx.doi. org/10.2105/AJPH.2005.075630 PMID:17463378

28. Flores SA, Mansergh G, Marks G, Guzman R, Colfax G. Gay identity-related factors and sexual risk among men who have sex with men in San Francisco. AIDS Educ Prev. 2009;21(2):91103. http://dx.doi.org/10.1521/aeap.2009.21.2.91 PMID:19397432 